This item was submitted to Loughborough's Research Repository by the author.

Items in Figshare are protected by copyright, with all rights reserved, unless otherwise indicated.

\title{
Using LIWC to choose simulation approaches: A feasibility study
}

PLEASE CITE THE PUBLISHED VERSION

https://doi.org/10.1016/j.dss.2018.04.002

PUBLISHER

(c) Elsevier

VERSION

AM (Accepted Manuscript)

PUBLISHER STATEMENT

This paper was accepted for publication in the journal Decision Support Systems and the definitive published version is available at $\mathrm{https}: / /$ doi.org/10.1016/j.dss.2018.04.002

\section{LICENCE}

CC BY-NC-ND 4.0

\section{REPOSITORY RECORD}

McHaney, Roger, Antuela Tako, and Stewart Robinson. 2018. "Using LIWC to Choose Simulation Approaches: A Feasibility Study". figshare. https://hdl.handle.net/2134/32837. 


\title{
USING LIWC TO CHOOSE SIMULATION APPROACHES: A FEASIBILITY STUDY
}

\author{
Roger McHaney, Antuela Tako and Stewart Robinson
}

\begin{abstract}
Can language usage help determine which model approach is best suited to provide decision makers with desired insights? This research addresses that question through an investigation of Linguistic Inquiry and Word Count (LIWC), which calculates the presence of more than 80 language dimensions in text samples, and permits construction of custom dictionaries. This article demonstrates use of LIWC to ensure better problem/model fit within the context of selecting a decision support tool. We selected two simulation tools as research instruments to investigate a broader question on the usefulness of LIWC to guide choice of DSS tool. The tools selected were System Dynamics (SD) and Discrete Event Simulation (DES). First, we tested LIWC to analyze practitioners' language use when developing models. LIWC pointed out significant linguistic differences consistent with prior theoretical work, based on model development approach in a number of dimensions. These differences provided a basis for developing a custom dictionary for use on the second part of our study. The second part of the study focused on language used by decision makers in problem statements and used the linguistic clues identified in the first part of the study to ensure problem/model fit. Results indicated problem statements contained linguistic clues related to the type of information desired by problem solvers. The article concludes with a discussion about how LIWC and similar tools can help determine which DSS tools are suited to particular applications.
\end{abstract}

Keywords: Linguistic Inquiry and Word Count(LIWC), text analytics, Problem Solving, Tool Choice, Discrete Event Simulation, System Dynamics

\section{INTRODUCTION}

Model developers perceive problems from a variety of perspectives which may not always match the way decision makers describe these problems. Their world-views are influenced by prior experiences, skill, nationality, industry affiliation, education, and other factors [1]. They are apt to build models and structure solutions to problems according their unique background. Some decision makers focus 
on strategic outcomes while others may look for tactical or even operational outcomes. Determination of appropriate problem-solving approaches may be key to eventual project success [2]. Of course, inappropriate choice of decision support tools can result in poor, suboptimal or flawed decisions--although it is possible that poor decisions may lead to good outcomes which provide a false sense of control $[3,4]$. While many considerations go into a decision-making process, those which reduce uncertainty and help align outcomes with decision maker intention is worth exploration and consideration [5,6]. Arnott summarizes nicely, "[t]he objective of a DSS project is usually to improve the decision process and outcome for a manager making an important decision.” [4] In other words, the problem-solver must clarify decision objectives, scope, and desired outcomes; and clearly understand the target decision's nature. This necessitates structured conceptual modelling clearly suited to the problem situation [7].

Our current article explores a potential method to mitigate this dilemma using analysis conducted with Linguistic Inquiry and Word Count or LIWC. "LIWC is a transparent text analysis program that counts words in psychologically meaningful categories," [8] and has a default dictionary with more than 80 psychologically meaningful dimensions. It also permits construction of corpus-specific custom dictionaries. This article investigates use of this tool within the decision support domain. Specifically, we describe how LIWC can be used by decision support practitioners to better ensure a model fits a problem in relevant circumstances.

A variety of choices exist in decision support systems in terms of tools available $[9,10]$, approaches used [11,12], and outcome desired [5]. In the current study, we focus on two of these: system dynamics (SD) and discrete event simulation (DES). Both enable decision-makers to understand realworld systems while they build and experiment with models. Both tools are used in a wide range of areas and for many purposes [13,14]. Appropriately selecting modeling approaches and other key indicators can influence model outcomes [15]. For instance, when using a tool such as SD, a goals are often strategic. On the other hand, DES models often are characterized by specific details and operational objectives. Use of the wrong tool to develop a system model could result in poor outcomes that do not offer germane information to problem-solvers. 
The current study seeks to demonstrate that how a linguistic analysis of problem statements can better guide a choice between SD and DES.

\subsection{Motivation}

Having two tools with similar levels of difficulty, used by equivalent groups of analysts, but intended for different areas of practice offers an opportunity to explore differences in language usage. Since each tool is appropriate for different uses, we expected this difference to be apparent in associated problem statements and other documentation related to model development. However, this may not necessarily be true. This common sense approach to problem solving may not match reality. As Espinosa et al. pointed out in a related study, "[their] tool could have been more helpful had the design matched the task.” [16] Reasons exist that may motivate analysts to choose a less-suited problem-solving tool. It may be a tool they have used in the past or have acquired expertise using. A person inexperienced in modeling might fall prey to a sales-minded software vendor who realizes their tool may not be the best choice for a particular problem domain but does not want to jeopardize a new customer prospect in a world filled with competition [14]. Likewise, analysts may not notice nuances of an unfamiliar system in the same way a system user might. For this reason, we believe useful clues may be embedded in problem statements, system descriptions or other documentation. Use of text analytics has the potential to make these visible. For these reasons, we believe comparison of SD and DES provides an ideal venue to assess whether a tool such as LIWC can add value to the decision-making process. And, in particular, to the point where tools are selected for later analytic phases of developing a problem solution.

\subsection{Study Overview and Approach}

Our general research question for this study is: Can language used to describe a problem help determine which decision-making technique is best suited? To answer this question, we first look at differences in analyst language usage when drawn from two domains of study under similar circumstances. This text was empirically collected in an earlier study which examined unique characteristics of DES and SD analysts while they built models for the same system [17-19]. The data from this study were used to determine if language usage varied between approaches. In the second 
part of the study, we examine the language used in problem statements generated by decision-makers to identify linguistic clues within their statements that could help to identify the most suited solution methodology.

\section{LITERATURE REVIEW}

\subsection{LIWC}

LIWC is a software system created by scholars at the University of Texas in Austin. Its psychological foundation rests on the concept that language usage is influenced by underlying emotional or cognitive states. This ultimately results in different word choice [20,21]. From a theoretical perspective, the tool supports the idea that deeper meanings in a person's communications will surface as a result of their word choices [22]. The speaker or writer may or may not be aware of this phenomenon at the time. While LIWC is rooted in this belief, other research indicates word choice may be more random and broader contextual considerations must be made [23]. The current research is aligned with the Pennebaker et al.’s [21] viewpoint.

LIWC uses more than 80 validated dimensions to classify more than 4,000 words or related word stems into these categories [24,25]. In essence, LIWC operates as a data processing system. Nearly any form of text can be loaded into the system. During its processing phase, LIWC compares every individual word from the input file(s) to a preloaded dictionary of words or their stems. Each is classified according to Pennebaker’s [8,26,27] validated dimensions. These dimensions were extensively validated by LIWC's developers and others using over one hundred million words from a large number of variety of sources $[8,26,27]$.

Many studies in a variety of areas have used LIWC for text classification and predictive outcome analysis $[28,29]$. In these studies, word use patterns emerge to inform observers of authors' underlying psychological states and infer a potential for future behaviour [30,31]. LIWC has a history of other uses as well. For instance, Chung and Pennebaker [25] describe studies ranging from examinations of mood disorders [32] to the nexus between demographics and personality [33] to community linguistic cohesiveness in writings found on Wikipedia and Craigslist [34]. Other research has reported correlations of individual's word usage with personality, and then predicted behaviours 
from this usage [35-38]. Another study, particularly relevant to this research, examined decision style and whether its presence can be revealed in language usage. This study used the context of clinical decision-making processes employed by physicians [39] and examined the dual process model [40] which suggests a continuum from intuitive to analytical decision-making represents most decision styles [41]. The gist of the study was to help clinicians recognize their decision-making style with deeper motivations to reduce clinical error [39]. This study collected physicians' speech data as they inspected dermatological images and developed a diagnosis. Data collection details were provided in a related study by Hochberg, Alm, Rantanen, DeLong, and Haake [42]. These studies found decisionmaking style manifested in language choice, and therefore, suggest cognitive processes do influence linguistics as claimed by Pennebaker and others [8,20]. Hochberg, et al. [39] also concluded that "in mission-critical environments, linguistic markers of decision-making style may be used to determine the optimal modes of reasoning for a particular task in high-stakes human factors domains.” [39] One advantage of LIWC is its non-invasive nature. Rather than observe a subjects' action, it permits a direct study of artifacts generated at an earlier time. Traditional psychological research often is susceptible to Hawthorne and related effects [43] or inherent shortcomings found in self-report studies [44]. These collections methods may be useful in theory validation. However, business scenarios like purchasing decisions, sales campaigns, or decision support methodology selection, often require that analysts understand early signals which can influence predictive or pre-emptive choices [45].

\subsection{Simulation}

Use of computer simulation modeling continues to grow, particularly with benefits provided by recent advances in computer hardware, software, analytics tools, and internet connectivity. These advances increase use of simulation techniques for problem solving and decision making. [46,47]. From a fundamental perspective, simulation models comprise three components: (1) input variables, often represented by distributions of possible values to describe the system being modeled; (2) software systems and modeling approaches used to process input variables; and (3) the resulting outputs, often represented statistically or visually to help decision makers assess possible courses of action. Two common forms of simulation software are system dynamics and discrete event simulation $[46,48,49]$. 
Each simulation project is unique and specific aspects of problems being analyzed may require distinctive considerations [50,51]. That being said, seasoned modelers and experts provide general approaches for transforming real world problems into useful models and eventually information for decision makers. Often, experts prescribe use of lifecycle models which provide a series of steps, phases or guidelines that enable model developers to proceed in an organized fashion $[46,48,52-59]$. At a point in time within these lifecycles, a modeler must determine the tool needed to provide the desired output. Generally, this activity takes place in an early phase.

While the specifics may be debated, one fact is clear: at some point, a modeling tool and approach are required. This decision may be influenced by many factors including: modelers’ experience and expertise; available toolset; past experience; and world view. This may result in use of tools which are not as well suited. The differences between SD and DES are next illustrated.

\subsection{SD/DES Modeling Overview}

System Dynamics models help understand complex systems behavior over a set interval [60]. This complexity is built into SD models using structures such as stocks connected with feedback loops and flows. The dynamic, time-based nature of the models ensures complex and nonlinear behaviors emerge in the simulated system. Interrelationships between variables within the model result in cause and effect actions as updates occur [49]. In general, the underlying policy structure and continuous behaviors create a layer upon which specific events and decisions exist and are impacted by the intricacies of the system [61,62]. SD models are often strategic and policy driven, and have been used to simulate scenarios that include the impact of government or corporate decision making, mining [63], public health [64], waste water management [65] and many others [13].

Discrete Event Simulation is a broadly applied form of modeling used to represent real-world systems in varying levels of detail. Generally, DES supports decision-making in engineering, operations management, logistics, heath care, and other business areas. DES models often represent a specific physical system, that will be constructed or changed. DES's detailed nature has resulted in a wide range of modeling tools tailored to specific niche areas such as transportation, assembly lines, train travel, machining centers and so forth. The scope of most DES models is situated at tactical or 
operational levels. Conceptually, DES models represent constrained resource elements used by entities which move through the system over time. A primary characteristic of DES is that blocks of time may pass with no changes to system state. Events utilize future and current event chains as a mechanism for scheduling discrete changes which impact various elements of the model at specific points in time [46].

DES and SD have been compared and contrasted in past studies [66] with some perspectives influenced by researchers’ past experiences and pre-existing knowledge [67]. Although the approach used in each modeling technique is different, their use can be complementary with each offering different strengths [66]. However, in some cases, strengths are overlooked due to the influence of other factors [68]. A number of authors comment about the differences between DES and SD. Among others these include the operational nature of DES contrasting with the strategic nature of SD [69]. In general, DES was shown to be operational [69], discrete [67], stochastic [66,67,70], detailed [46,54], analytic [69], linear [66], network-oriented [67], open-process structured [70], implicit [66] and suited to decision-makers at the operational or tactical levels [69]. SD, on the other hand was strategic [69], continuous [67], holistic [69], deterministic [66,67,70], aggregate [46,54], broad, non-linear [66], explicit [66], feedback oriented [71], and suited to policy makers [69].

A research stream developed by Tako and Robinson systematically approached DES and SD differences from both end-user [17] and empirical perspectives [18,19]. In the empirical studies, Verbal Protocol Analysis (VPA) uncovered the mental processes used by experts as they constructed a simulation using their preferred technique $[18,19,72]$. The subjects spoke aloud throughout their modeling process. Spoken words were collected and used to highlight theoretical similarities and differences in the two techniques. Patterns emerged and formed the basis for insights. Details of the differences and similarities found are provided in Tako and Robinson [17, 18] and Tako [19].

Although the current study emphasizes differences between SD and DES, many commonalties also exist. In at least one state-of-the-art modeling tool, capabilities of both approaches are incorporated [73]. This means caution must be taken to ensure the approach meshes with desired outcomes. For 
instance, a strategic problem analysed with a DES approach may not provide data as well suited for decision-making as data analysed with an SD approach. Likewise, a detail-oriented operational problem might not be well suited to analysis using an SD approach, which aggregates individual values compared to DES. Therefore, having a better understanding about the problem and the desired outcomes is important.

\section{DO SD AND DES ANALYSTS USE A DIFFERENT LANGUAGE?}

\subsection{Methods}

We initially assessed differences hypothesized to exist between DES and SD approaches to simulation as reflected in the linguistic clues embedded in analysts' language through an examination of narrations collected as they developed a simulation in their area. Data used in the current study was collected during research by Tako and Robinson $[17,18]$ in their quest to better understand the differences between SD and DES modeling approaches. The inquiry “conducted a quantitative comparison of expert modelers' thinking, looking at their attention during the modeling process and more specifically the modeling stages they think about while building simulation models.” [18]. An empirical data set was developed as part of this effort. The idea was to ask expert modelers from each domain to speak their thoughts as they progressed through the development process. Their words were collected verbatim, typed into a word document and analysed using the qualitative research method, Verbal Protocol Analysis [74].

The initial Tako and Robinson [18] study used a UK prison problem based on prior research in SD [75] and DES [76-78] The particular UK prison population scenario was based on Grove, Macleod and Godfrey [79] who specified prisoners that entered as first time offenders could later become recidivists. As originally described by Tako and Robinson [18], the current data collection process focused on prison overcrowding issues and asked experts to develop a model used to explore solutions. Modelers contemplated two potential outcomes: (1) increase prison capacity to facilitate more rigid rules regarding early release and recidivism; or (2) decrease capacity and provide enhanced social programs and other incarceration alternatives. Ultimately, the experts developed a decision support model which implies some items might be variable for what-if testing by policy makers and 
those familiar with the problem. Modelers were screened to ensure all used the appropriate modeling technique as part of their job functions and performed their tasks using appropriate software tools. Each participant was employed by a UK-based simulation software or consultancy company, and held at least a masters' degree in a relevant field. Their industry simulation experience ranged from four to twenty years.

\subsection{Data Collection}

Data were collected using VPA as reported by Tako and Robinson [18]. This study implied the VPA data would provide abundant linguistic material for a DES and SD comparison due to the "richness of information and the live accounts it provides on the experts' modeling process.” [18]. This technique offered control and the ability to capture a complete representation of the modeling process directly from experts as they worked. The subjects received the case study and built models. They were encouraged to verbalize their thoughts and actions. These audio recordings were collected and later transcribed into anonymous text files designated as either DES or SD.

Since VPA is an intrusive data collection technique, particular care was taken to ensure modelers understood that they needed to speak their thoughts aloud in a natural manner as if talking to themselves while creating a model. To help put the subjects at ease and create a relaxed atmosphere, a series of three short warm-up exercises were run where the research team trained the subjects on how to verbalize their thought process clearly and effectively [80].

Researchers checked the collected data for accuracy and took steps to eliminate data problems as recommended [21,26]. This included fixing misspellings, replacing abbreviations, eliminating contractions, and removing sentence end markers, among other commonly identified potential problems. Then the data was reanalysed using LIWC text analysis [21].

\subsection{Testing for Differences}

The underlying research premise was that modelers using DES or SD techniques would think differently during the simulation process and these differences would manifest in language selection nuances across various thresholds. These variations, as measured by LIWC dimensions, were expected to reflect underlying differences in thinking. LIWC used both qualitative and quantitative 
text analysis techniques to identify characteristics common to each text sample which were statistically tested for significant differences. The language differences between DES and SD simulation experts were hypothesized to be suitable for a linguistic analysis. In general, we expected simulation experts would use language specific to aspects of their modeling approach. For instance, analysts using DES would use detailed and operational word choices while those using SD would use broader, holistic terms. In all, 22 dimensions available in LIWC were compared for language use. Table 1 provides a summary of LIWC dimensions and the hypothesised matching simulation approach: SD or DES.

\begin{tabular}{llc} 
Table 1 - LIWC categories by simulation approach (SD, DES) it matches theoretically \\
\hline LIWC Dimension & Descriptive Text & $\begin{array}{c}\text { Simulation } \\
\text { approach }\end{array}$ \\
\hline Words > 6 Letters & Broader, policy-level language. & SD \\
Second Person & Holistic, explicit language; Often used in training. & SD \\
Insight & Policies; high level decisions. & SD \\
Causation & Big picture; insight; cause and effect. & SD \\
Certainty & Deterministic & SD \\
Inclusive & Feedback; big picture; holistic & SD \\
Exclusive & Feedback loops & SD \\
Achievement & Goal setting; policies; strategies & SD \\
Personal Pronouns & Operational; individual representations & DES \\
Affective Processes & Operational; individualistic & DES \\
Tentative & Stochastic; disruptions; rare events possible & DES \\
Discrepancy & Stochastic; discrepancies & DES \\
Inhibition & Uncertainty; detailed; finer resolution & DES \\
Perception & Observing, hearing, feeling; visual, perceptual & DES \\
Seeing & Detailed; operational & DES \\
Relativity & Detailed; physical relationships; time; distance & DES \\
Motion & Detailed; physical relationships; time; motion & DES \\
Time & Time-based; detailed & DES \\
Space & Detailed; physical layouts; design & DES \\
Work & Operational; human component & DES \\
Question & Detail oriented & DES \\
Emotion & Operational; human process modeling & DES \\
\hline
\end{tabular}

\subsection{Analysis and Results}

Ten text samples were categorized as SD or DES and aggregated (5 each). The data were cleaned to remove misspellings or errors. The DES transcript averaged approximately 5,400 words each. The SD transcripts were shorter with an average of approximately 3,800 words each. The samples were pretested for cognitive complexity and fluency levels [8]. No significant differences were found. A number of the t-tests were significant at the $\mathrm{p}<.10$. Table 2 provides the results. Additional details related to the differences are reported in McHaney, Tako and Robinson [81] 
Table 2 - Significant differences between the SD and DES transcripts tested with LIWC

\begin{tabular}{ccc}
\hline LIWC Dimension & Expected to Score Higher & p \\
\hline Words $>6$ Letters & SD & .004 \\
Insight & SD & .089 \\
Personal Pronouns & DES & .033 \\
Inhibition & DES & .062 \\
Perception & DES & .011 \\
Seeing & DES & .001 \\
Relativity & DES & .064 \\
Motion & DES & .001 \\
Question & DES & .043 \\
\hline
\end{tabular}

Based on the results of the testing, it can be surmised that LIWC identified significant linguistic differences in the language used in each simulation approach in a number of dimensions. This is consistent with prior theoretical work; hence we concluded LIWC can be used to analyse analyst language.

In linguistic analysis such as LIWC, a large collection of texts is assembled to develop norms for patterns occurring in language [82]. We conducted further analysis to gain insight regarding the SD and DES corpuses when compared to the Expressive Writing and Natural Speech corpuses used to develop LIWC. Expressive Writing norms include texts from people ranging in age from elementary students to the elderly who are asked to write about deeply emotional topics. Natural Speech norms on the other hand were developed from diverse transcripts from multiple contexts where people wore audio recorders, couples discussed personal issues, and people were recorded in public spaces [83]. The comparison of the SD and DES corpuses with the LIWC corpus norms for Expressive Writing, Natural Speech, and the overall norms [83] are provided in Appendix A. This comparison provides additional insight into the differences and similarities between how language use differs between SD and DES modelers, as well as how it differs from people communicating via various forms of writing and speech. While much of the information contained in the appendix is outside the scope of the current study, it is interesting to note that the SD and DES corpuses match particular characteristics of the various forms of communication and have less in common with others. For example, use of personal pronouns occurs much less frequently in DES and SD corpuses. Since VPBA was used to collect the SD and DES data, many aspects of the natural speech corpus match closely. In general SD and DES exhibit fewer emotion-related words and more numeric and causal words. SD and DES tend to have higher levels of future focused words whereas Expressive Writing and Natural Speech have 
more of a past focus. Further norms can be obtained from the LIWC Language Development Manual [83].

\section{PREDICTING MODELING TECHNIQUE FROM PROBLEM STATEMENT}

We next turned our attention to text describing problem statements, with the view to examine whether LIWC can be used to answer questions of a wider scope, that is: can LIWC help identify the correct modeling approach based on the language used to describe the problem?

\subsection{Data Collection}

Seventeen problem statements were collected from existing, published simulation studies. The statements were edited and formatted, and references to the modeling tools used were removed where mentioned. The text was retained in its original form to ensure no clues were distorted or lost. The text files were between 196 to 845 words long, averaging 454 words the cases from SD material and 467 for DES cases. In addition, the modeling technique used by the study authors was collected. Table 3 provides the details.

Table 3 - Cases Used in Current Study

\begin{tabular}{llccc}
\hline $\begin{array}{l}\text { ID } \\
\#\end{array}$ & Domain of Study & $\begin{array}{c}\text { Modeling Technique Used by } \\
\text { Study Authors }\end{array}$ & $\begin{array}{c}\text { Word } \\
\text { Count }\end{array}$ & Reference \\
\hline 1 & Hospital System & DES & 313 & {$[84]$} \\
2 & Family Practice System & DES & 509 & {$[85]$} \\
3 & Snack Foods Warehouse & DES & 421 & {$[86]$} \\
4 & Lean Manufacturing & DES & 563 & {$[87]$} \\
5 & AGV System & DES & 478 & {$[88]$} \\
6 & Supermarket Checkout System & DES & 282 & {$[89]$} \\
7 & Sugarcane Mill & DES & 767 & {$[90]$} \\
8 & Banca d'Italia Back Office & DES & 364 & {$[91]$} \\
9 & UK Prison System & C++ Flow Model & 462 & {$[18,79]$} \\
10 & Water System Model & SD & 527 & {$[65]$} \\
11 & Urban Growth & SD & 419 & {$[92]$} \\
12 & Swamping & SD & 477 & {$[92]$} \\
13 & Words of Mouth & SD & 441 & {$[93]$} \\
14 & Peace Shield Program & SD & 343 & {$[94]$} \\
15 & Stichting Rechtsbijstand Policy & SD & & {$[95]$} \\
& Simulation & & 845 & {$[96]$} \\
16 & Airline Management & SD & 196 & {$[96]$} \\
17 & Sales Process Employee Morale & SD & 342 & {$[97]$} \\
\hline
\end{tabular}

\subsection{Building on the First Experiment}

Decision-makers may not be familiar with a discipline's lexicon; however, hints may exist within the language they use to provide guidance to those seeking ways to solve the problem. As demonstrated 
earlier, in its predefined dictionary, LIWC uses word counts that fall into validated categories. Measures of word use incidence and frequency scores are generated for all text in the analyzed samples. This approach takes advantages of prior validation work and offers an easy analysis method [98]. However, when the existing dictionary initially was used for an analysis of the collected problem statements, the results were not satisfactory. Several of the problem statements discriminated correctly, but many did not. We specifically paid attention to the categories that were determined to be significant (as displayed in Table 2).

Several reasons may exist for this situation. In the first part of the study, the analysts were speaking and were specifically using a modeling approach. This left no ambiguity in their efforts. In the second part of the study, the decision-makers made the problem statements. These statements were not focused on the methodology but rather on acquiring desired information. Therefore, we used an alternate approach and developed custom LIWC dictionaries from the material collected for the first experiment.

\subsection{Building a Custom LIWC Dictionary}

Creation of a custom dictionary was motivated by understanding that unique linguistic traditions emerge in a particular discipline [99]. While the concept of pre-constructed dictionaries is appealing due to ease of use and lower costs, "it is also the case that they are frequently context-dependent, potentially leading to serious errors in research” [100]. Therefore, constructing distinct, custom dictionaries is appealing but the costs are often high and can slow down an analysis [101]. In the current study, linguistic clues, generally recognized by subject-matter experts, provide hints regarding the best approach to solving a problem. For instance, Tako and Robinson [18] identified characteristics unique to SD and DES approaches to modeling. These characteristics were proactively distilled into words typical to the modeling approach in each area. A specialized corpus of data, like simulation problem statements, has language specialized to that field [102]. For this reason, lists of words specific to their respective areas were created for both DES and SD.

Custom dictionaries are generated using various methods. Rice and Zorn [103] describe general approaches. In one, they suggest that machine learning should approach the process by "classifying or 
scoring a subset of texts (usually documents) on their sentiment, and then using their linguistic content to train a classifier” [103]. In another approach they suggest "dictionary-based approaches [that] begin with a predefined dictionary of positive and negative words, and then use word counts or other measures of word incidence and frequency to score all the opinions in the data” [103]. Both approaches are highly dependent on having high quality data with comprehensive values based on theory.

Fortunately, in this dictionary creation process, a strong theoretical basis for differences between SD and DES exist in prior research $[17,19]$. Therefore, it made sense to utilize Zorn's dictionary approach. The process was enhanced using processes recommended by Pennebaker et al. [26] to transform theoretical constructs into a useful dictionary of key domain-specific words [26]. The custom dictionary used the corpus of material collected using VPA in the study of SD and DES development processes as described in the first study of this article [18,19]. Initially, 785 unique words were identified in the SD material and 939 were identified in the DES material. An iterative process was used to remove overlapping terms, clearly non-discriminating words and low-usage words. The process utilized database technology to make the comparisons and ensure a corpus resulted that could clearly differentiate between SD and DES. A final iteration utilized theoretical values to fine-tune the dictionary. Table 4 provides several example words and word stems in the dictionary.

Table 4 - Example dictionary words and word stems

\begin{tabular}{lc}
\hline Word/Word Stem & Technique \\
\hline entity & DES \\
equilibrium & SD \\
exogenous & SD \\
Feedback & SD \\
Flow* & SD \\
function* & DES \\
General & SD \\
Goalseeking & SD \\
Guess* & SD \\
Holistic & SD \\
Indistinguishable & SD \\
Influence & SD \\
\hline
\end{tabular}


The validity of a custom dictionary relies heavily on data quality and comprehensiveness in the way the dictionary captures specialized aspects of language use in the relevant texts [100]. Therefore, the current study’s DES and SD custom dictionaries were validated with a multi-method approach suggested by Rice and Zorn (2013). The classified words were provided to 4 modeling experts, with over 15 years of simulation experience. They were asked to determine the degree of association with each methodology. Non-consensus words were removed and the resulting dictionary was used in subsequent experiments. Eventually 70 words were added to the custom dictionary. Of these, 38 were associated with DES and 32 with SD.

\subsection{Results of Analysis with Custom LIWC Dictionary}

After validation, the custom dictionary’s corpus was used to classify the 17 problem statements. Using a commonly accepted analysis approach, each text file was automatically segmented into 3 portions by the LIWC software [21,104]. A sample size of 51 text snippets was produced. SD and DES scores were generated for each segment. These were further classified as incorrect or correct using against the modelling technique used in the published study associated to each problem definition . The classification was tested using an ANOVA in SAS 9.4. The results were significant and indicated the custom dictionary was able to distinguish between SD and DES problem statements $(\mathrm{F}=42.82, \mathrm{p}<.000)$. The analysis also determined DES statements discriminated correctly $(\mathrm{F}=21.6$, $\mathrm{p}<.000)$. Likewise, SD problem statements correctly classified $(\mathrm{F}=22.7, \mathrm{p}<.000)$. For the DES problem statements, correct identification yielded a mean score of 2.28, standard deviation=1.26 versus mean $=.808$, standard deviation $=.986$ for $\mathrm{SD}$ cases tested as DES. SD cases scored an average of mean=2.24, standard deviation=1.98 versus mean=.237, standard deviation=.459 for DES cases tested as SD. Overall, the results supported the validity of the custom dictionary and its capability to discriminate correctly between SD and DES problem statements. Table 5 summarizes the results. 
Table 5 - Results summary

\begin{tabular}{|c|c|c|c|c|c|c|}
\hline ID \# & Domain of Study & $\begin{array}{l}\text { Expected } \\
\text { Outcome }\end{array}$ & $\begin{array}{c}\text { Score } \\
\text { Related to } \\
\text { Expected } \\
\text { Outcome }\end{array}$ & $\begin{array}{l}\text { Score for } \\
\text { Opposite } \\
\text { Outcome }\end{array}$ & Difference & Classification \\
\hline 1 & Hospital System & DES & 5.5 & 0.92 & $4.58^{*}$ & Correct \\
\hline 2 & Family Practice System & DES & 3.99 & 2.85 & $1.14^{*}$ & Correct \\
\hline 3 & Snack Foods Warehouse & DES & 8.54 & 0 & $8.54^{*}$ & Correct \\
\hline 4 & Lean Manufacturing & DES & 6.33 & 0 & $6.33^{*}$ & Correct \\
\hline 5 & AGV System & DES & 8 & 0 & $8^{*}$ & Correct \\
\hline 6 & Supermarket Checkout & DES & 6.38 & 0 & $6.38^{*}$ & Correct \\
\hline 7 & Sugarcane Mill & DES & 4.3 & 1.57 & $2.73^{*}$ & Correct \\
\hline 8 & Banca d'Italia & DES & 11.56 & 0.83 & $10.73^{*}$ & Correct \\
\hline 9 & UK Prison System ${ }^{+}$ & SD or DES & 0 & 0.64 & $-0.64^{* *}$ & Indeterminant \\
\hline 10 & Water System Model & SD & 7.38 & 2.29 & $5.09^{*}$ & Correct \\
\hline 11 & Urban Growth & SD & 19.19 & 1.42 & $17.77^{*}$ & Correct \\
\hline 12 & Swamping & SD & 8.18 & 1.89 & $6.29^{*}$ & Correct \\
\hline 13 & Words of Mouth & SD & 4.53 & 3.88 & $0.65^{*}$ & Correct \\
\hline 14 & Peace Shield Program & SD & 6.15 & 1.74 & $4.41^{*}$ & Correct \\
\hline 15 & Stichting Rechtsbijstand & SD & 3.55 & 1.42 & $2.13^{*}$ & Correct \\
\hline 16 & Airline Management & SD & 6.11 & 1.52 & $4.59^{*}$ & Correct \\
\hline 17 & Sale Morale ${ }^{++}$ & SD & 5.27 & 7.02 & $-1.75^{*}$ & Incorrect \\
\hline $\begin{array}{l}+ \\
++ \\
+ \\
* \\
*\end{array}$ & $\begin{array}{l}\text { The analysis was not able to conclusi } \\
\text { either SD or DES problem solving. } \\
\text { This case was classified as SD which } \\
\text { was a description of the system from } \\
\text { problem statement. Expert modelers a } \\
\text { Significant at } p<.001 \\
\text { not significant at } p=.042\end{array}$ & $\begin{array}{l}\text { ly provide a recon } \\
\text { as the technique u } \\
\text { process perspective } \\
\text { reed that the proble }\end{array}$ & $\begin{array}{l}\text { ded modeling ap } \\
\text { y the model deve } \\
\text { ter in the article a } \\
\text { atement indicatec }\end{array}$ & $\begin{array}{l}\text { for this case } \\
\text { On closer ins } \\
\text { model was cre } \\
\text { ter fit with DE }\end{array}$ & $\begin{array}{l}\text { le case had been c } \\
\text { ion, the problem } \\
\text { but it was not bas } \\
\text { deling. }\end{array}$ & $\begin{array}{l}\text { structed to work for } \\
\text { tement in the article } \\
\text { on the provided }\end{array}$ \\
\hline
\end{tabular}

\section{DISCUSSION}

Our study began with the guiding question: Can language usage help determine which decisionmaking technique is best suited? This question is not unique to the decision support field. As mentioned in our literature review, Hochberg and colleagues investigated a similar question in medical situations where life and death decisions are routinely made [39,42]. Hochberg et al. suggested more knowledge about a situation could add value to the decision-making process and suggested linguistic clues should become a key component. Our findings supported their suggestions and specifically expanded their ideas into simulation and modeling decision-making arena. Our research suggested that word selection and usage by decision-makers and those formulating problems may reveal subtle dimensions that can help steer the decision making process and enhance solution development. Many tools can be applied to any problem and influence the eventual course of action. Even a slight improvement can result in better outcomes. The current research findings described how insight was gained by paying attention to the little words in big data [25]. Like Hochberg et al. [42], 
we found linguistic clues using text analytics. These clues were present in both problem statements and problem solution approaches.

Specifically, our research was conducted through a preliminary investigation of the text analysis tool, Linguistic Inquiry and Word Count (LIWC). We demonstrated how LIWC can be used by decision support practitioners to ensure a better problem/model fit. Our first study compared development processes of simulation practitioners using VPA [19]. Theoretical differences were hypothesized based on prior research and used to develop hypotheses. Text transcripts were analysed using LIWC and distinctive linguistic features were found. The second part of the study focused on language usage by decision makers. Results indicated problem statements did contain linguistic clues related to the type of information desired by the problem solvers.

In general, our study built on earlier work $[18,19]$ and relied on existing DES and SD literature to validate LIWC’s consistency with theoretical features prominent in each modeling approach. Concepts and perspectives developed by social psychologists worked as a lens to suggest which modeling tool better aligns with a particular problem. We believe clues within decision-makers' language are relevant to selecting an appropriate modeling approach and this is important during early phases in the simulation process. In general, the results indicated particular psychological dimensions are unique to either DES vs. SD modeling. This was consistent with prior research and academic opinions $[18,19]$. These differences were discovered in language dimensions specifically measured by LIWC.

The second part of the study focused on a realistic problem faced by decision makers---which modeling tool should be employed based on the problem. Different problems require different toolsets and decision-making approaches. Additionally, problems faced by decision makers generally include unique elements [50,51]. That being said, seasoned modelers and experts can provide general approaches for transforming real world problems into useful models and eventually information for decision makers. These approaches may manifest as lifecycle models which provide a series of steps, phases or guidelines that enable model developers to proceed in an organized fashion [53] or experts 
may carry these out intuitively. At a point in time within these life cycles, a modeler must determine the tool needed to provide the desired output. Generally, this activity takes place in an early phase. From a practical perspective, clients of a decision-making process are unlikely to load the discussion with a preconception of the modeling approach that should be adopted. Clients normally would not know which approaches were available. They want help and sense that modeling and analysis might provide that help. So descriptions of the problem may not have a solution approach bias. It was important that a custom dictionary was created using terms likely to be spoken when describing a problem best solved with one approach or another. These words were based on theory. When this was done, as seen in Table 5, two cases presented unique circumstances. In all other instances, linguistic clues correctly identified the solution technique used by experts conducting the study. The first anomaly was case \#9, the UK Prison model. Its history coincides with the classification outcome. It specifically had been developed and worded to be method-agnostic. The case was developed for the modeling expert that would be asked to participate in the VPA experiment. It appears the case was in fact, neither worded in a way that suggested an SD or DES approach [17]. The other misclassification occurred with case \#17. This model was based on a published account of an SD model development intended to model employee morale. In this study, Kristekova et al. [97] developed a problem statement (pp. 462-463) that was largely process-oriented . If the model had been based solely on this description, we believe a DES model would have been best suited to the effort. However, model goals and objectives did not include using this description as a part of the simulation effort. This problem statement provides a caution to model developers. It is important not to use automatic discrimination and linguistic clues as the entire decision process. Rather, it should be part of the process, rather than sole determination of a direction to take.

All other cases (fifteen total) scored significantly higher with the technique expected. These findings supported our belief that text analytics can be useful in acquiring additional knowledge regarding the appropriate direction to take in developing a simulation. We believe domain-specific language is a largely untapped resource in decision support that decision-makers and problem-solvers should consider. Since analysts come to a project with varied perspectives that are influenced by their education, experiences, successes, and knowledge, preconceived biases are likely to emerge. So, any 
new source of knowledge can be useful if used appropriately. Hochberg, et al. summarize this idea nicely by saying, "in mission-critical environments, linguistic markers of decision-making style may be used to determine the optimal modes of reasoning for a particular task in high-stakes human factors domains.”[42]

This study's outcomes suggest the need for related research. The findings verify the presence of linguistic clues in problem statements and suggests this knowledge should be applied in ways that add value to the problem-solving process. The modeling team needs a strategy for implementation and choice of appropriate simulation tools. They must decide if mathematical, process, agent-based, systems dynamics, discrete event, continuous, or other types of modeling should be used. The team needs to determine if a simulation language, simulator, or traditional language should be chosen. Other options for a project also require definition. For instance, will an animation be required? What type of output is needed? What form should output take? Is prototyping applicable? As Balci [68] said, "The question is not to bring a solution to the problem, but to bring a sufficiently credible one which will be accepted and used by the decision maker(s).... Sometimes, the communicated problem is formulated under the influence of a solution technique in mind. Occasionally, simulation is chosen without considering any other technique just because it is the only one the analyst(s) can handle.” (p.25) Based on our findings, we believe linguistic analysis helps provide insight toward resolving these issues.

\section{LIMITATIONS AND CONCLUSIONS}

This study does have several limitations which should be considered. First, the data set for the first part of the study was derived during staged settings, where the modelers knew they were under observation and were under the pressure of time and being studied as representative experts. The VPA approach also has inherent limitations. Like all protocol analysis approaches, individuals under observation may act differently [51]. Likewise, a risk exists that experts could fail to verbalize a portion of their cognitive processes or that elements of interaction and collaboration may be forgotten. Tako and Robinson [18] took reasonable precautions to preclude these problems during data collection but issues still remain due to the technique used. The task itself also could be considered a 
limitation and perhaps even related to reasons some hypothesized outcomes were found not significant. The prison model was structured to ensure timely completion of the data-collection exercise. Additionally, the subject was less physical in manifestation than a manufacturing or industrial model. Another limitation is the sample size. Both the number of problem statements analysed (e.g. 17) and the number of experts (e.g. 10) was small. Therefore, more observations might have provided more representative results. Another limitation is the LIWC software. While it checks for over 80 validated dimensions, many others may exist that are not being examined. Likewise, specialty language use might not be exactly categorized as expected. And additional work may have located additional and better discriminators. Finally, the alignment of the LIWC dimensions with the hypothesized differences between SD and DES use is open to some subjectivity, and so we must be cautious about the interpretation of the results.

Considering the limitations, we believe this study is a first step for future work. Larger samples, the use of different models in other problem domains could provide additional insights. In this study LIWC was used to analyse the data. Other word analysis approaches and tools such as the General Inquirer at Harvard University [105], and the Multi-Perspective Question Answering (MPQA) Subjectivity Lexicon [106] at the University of Pittsburgh could be also used. Furthermore, the LIWC approach could be extended or complemented based on these tools to offer new approaches for the identification of linguistic clues.

Overall, this study suggests linguistic clues exist which can be important to selection of an appropriate modeling approach. This premise was validated with data from an empirical study that compared SD and DES techniques. The primary results of the study were consistent with theory and academic conjecture and provided knowledge that could be used in the better selection of an appropriate modeling method. In addition, we used LIWC as a technique to provide knowledge in decisionmaking by examining underlying cognitive processes through language use. The ideas used here can be implemented in other studies where written and verbal qualitative data is available.

\section{REFERENCES}

[1] F. Musso, B. Francioni, The Influence Of Decision-Maker Characteristics On The International Strategic Decision-Making Process: An SME Perspective, Procedia -Social and 
Behavioral Sciences. 58 (2012) 279-288. doi:10.1016/j.sbspro.2012.09.1002.

[2] L.R. Beach, T.R. Mitchell, A contingency model for the selection of decision strategies, Academy of Management Review. 3 (1978) 439-449. doi:10.1177/0022022108314549.

[3] J. Greenberg, "Forgive Me, I'm New”: Three Experimental Demonstrations of the Effects of Attempts to Excuse Poor Performance, Organizational Behavior and Human Decision Processes. 66 (1996) 165-178.

[4] D. Arnott, Cognitive biases and decision support systems development: a design science approach, Information Systems Journal. 16 (2006) 55-78.

[5] J.P. Shim, M. Warkentin, J.F. Courtney, D.J. Power, R. Sharda, C. Carlsson, Past, present, and future of decision support technology, Decision Support Systems. 33 (2002) 111-126.

[6] G.L. Sanders, J.F. Courtney, A field study of organizational factors influencing DSS success, MIS Quarterly. (1985) 77-93.

[7] S. Robinson, Conceptual modelling for simulation Part II: A framework for conceptual modelling, Journal of the Operational Research Society. 59 (2008) 291-304. doi:10.1057/palgrave.jors.2602368.

[8] Y.R. Tausczik, J.W. Pennebaker, The Psychological Meaning of Words: LIWC and Computerized Text Analysis Methods, Journal of Language and Social Psychology. 29 (2010) 24-54. doi:10.1177/0261927X09351676.

[9] R.W. McHaney, D. White, Discrete event simulation software selection: an empirical framework, Simulation \& Gaming. 29 (1998) 193-215. doi:10.1177/1046878198292005.

[10] M. Binbasioglu, M. Jarke, Domain specific DSS tools for knowledge-based model building, Decision Support Systems. 2 (1986) 213-223.

[11] R.H. Bonczek, C.W. Holsapple, A.B. Whinston, Future directions for developing decision support systems, Decision Sciences. 11 (1980) 616-631.

[12] E.B. Kim, S.B. Eom, Decision Support Systems Application Development Trends (20022012), International Journal of Information Systems in the Service Sector (IJISSS). 8 (2016) $1-13$.

[13] A.A. Tako, S. Robinson, The application of discrete event simulation and system dynamics in 
the logistics and supply chain context, Decision Support Systems. 52 (2012) 802-815.

[14] J.J. Swain, Discrete event simulation software tools: Back to the future, OR/MS Today. 38 (2011) 56-69.

[15] M. Jahangirian, S.J. Taylor, T. Young, S. Robinson, Key performance indicators for successful simulation projects, Journal of the Operational Research Society. 68 (2017) 747-765. doi:10.1057/jors.2016.1.

[16] A. Espinosa, J. Cadiz, L. Rico-Gutierrez, R. Kraut, W. Scherlis, G. Lautenbacher, Coming to the wrong decision quickly: why awareness tools must be matched with appropriate tasks, in: SIGCHI Conference on Human Factors in Computing Systems, ACM, 2000: pp. 392-399.

[17] A.A. Tako, S. Robinson, Comparing discrete-event simulation and system dynamics : users ' perceptions, Journal of the Operational Research Society. 60 (2009) 296-313. doi:10.1057/palgrave.jors.2602566.

[18] A.A. Tako, S. Robinson, Model development in discrete event simulation and system dynamics: an empirical study of expert modellers, European Journal of Operational Research. 207 (2010) 784-794.

[19] A.A. Tako, Development and use of simulation models in Operational Research: a comparison of discrete-event simulation and system dynamics, University of Warwick, 2008.

[20] J.W. Pennebaker, L.A. King, Linguistic styles: language use as an individual difference, Journal of Personality and Social Psychology. 77 (1999) 1296-1312.

[21] J.W. Pennebaker, M.E. Francis, R.J. Booth, Linguistic inquiry and word count: LIWC, 2001.

[22] J.W. Pennebaker, M.R. Mehl, K.G. Niederhoffer, Psychological aspects of natural language use: Our words, our selves., Annual Review of Psychology. 54 (2003) 547-577.

[23] S. Deerwester, S.T. Dumais, R. Harshman, Indexing by latent semantic analysis, Journal of the American Society for Information Science. 41 (1990) 391-407. doi:10.1002/(SICI)10974571(199009)41:6<391::AID-ASI1>3.0.CO;2-9.

[24] C. Chung, J. Pennebaker, The Psychological Functions of Function Words, in: K. Fiedler (Ed.), Social Communication, Psychology Press, New York, 2007: pp. 343-359. doi:10.4324/9780203837702. 
[25] C. Chung, J.W. Pennebaker, Counting little words in big data: The psychology of communities, cultures, and history, Psychology Press, New York, 2012.

[26] J.W. Pennebaker, R.J. Booth, M.E. Francis, Operator 's Manual Linguistic Inquiry and Word Count, LIWC.net, Austin, Texas, 2007.

[27] J.W. Pennebaker, C. Chung, M. Ireland, A. Gonzales, R.J. Booth, The Development and Psychometric Properties of LIWC2007, University of Texas, Austin, Texas, 2007. doi:10.1068/d010163.

[28] K. Coussement, D. Van den Poel, Improving customer complaint management by automatic email classification using linguistic style features as predictors, Decision Support Systems. 44 (2008) 870-882.

[29] J. Huh, M. Yetisgen-Yildiz, W. Pratt, Text classification for assisting moderators in online health communities, Journal of Biomedical Informatics. 46 (2013) 998-1005.

[30] M. Fishbein, I. Ajzen, Belief, Attitude, Intention, and Behavior: An Introduction to Theory and Research, Addison Wesley, Reading, MA, 1975.

[31] I. Ajzen, M. Fishbein, Attitudes and the attitude-behavior relation: Reasoned and automatic processes, European Review of Social Psychology. 111 (2000) 1-33.

[32] N. Ramirez-Esparza, C.K. Chung, E. Kacewicz, J.W. Pennebaker, The psychology of word use in depression forums in English and in Spanish. Testing two text analytic approaches, in: 2008 International Conference on Weblogs and Social Media (ICWSM2008), Menlo Park, CA., 2008: pp. 102-108.

[33] S. Argamon, M. Koppel, J.W. Pennebaker, J. Schler, Automatically profiling the author of an anonymous text., Communications of the Association for Computing Machinery (ACM). 52 (2009) 119-123.

[34] J.W. Pennebaker, The secret life of pronouns: What our words say about us, Bloomsbury Press, New York, 2011.

[35] J. Mahmud, Why Do You Write This ? Prediction of Influencers from Word Use Psycholinguistic Analysis from text, Icwsm. (2014) 603-606.

[36] J. Golbeck, C. Robles, M. Edmondson, K. Turner, Predicting Personality from Twitter, in: 
IEEE International Conference on Social Computing, IEEE, 2011: pp. 149-156.

[37] A.J. Gill, S. Nowson, J. Oberlander, What Are They Blogging About? Personality, Topic and Motivation in Blogs., in: Third International AAAI Conference on Weblogs and Social Media, AAAI, San Jose, CA, 2009.

[38] F. Mairesse, M. Walker, Words Mark the Nerds: Computational Models of Personality Recognition through language, in: 28th Annual Conference of the Cognitive Science Society (CogSci 2006), Vancouver, 2006: pp. 543-548.

[39] L. Hochberg, C.O. Alm, E.M. Rantanen, Q. Yu, C.M. DeLong, A. Haake, Towards Automatic Annotation of Clinical Decision-Making Style, in: LAW VIII - The 8th Linguistic Annotation Workshop, Dublin, Ireland, 2014: pp. 129-138.

[40] J. Evans, Dual-processing accounts of reasoning, judgment and social cognition, Annual Review of Psychology. 59 (2008) 255-278.

[41] K.R. Hammond, Principles of organization in intuitive and analytical cognition (Report \#231), Boulder, CO., 1981.

[42] L. Hochberg, C.O. Alm, E.M. Rantanen, C.M. DeLong, A. Haake, Decision style in a clinical reasoning corpus, in: Proceedings of the BioNLP Workshop, Association for Computational Linguistics, Baltimore, MD, 2014: pp. 83-87.

[43] G. Wickstrom, T. Bendix, The "Hawthorne effect" - What did the original Hawthorne studies actually show?, Scandinavian Journal of Work, Environment and Health. 26 (2000) 363-367. doi:10.5271/sjweh.555.

[44] P.M. Podsakoff, D.W. Organ, Self-reports in organizational research: Problems and prospects, Journal of Management. 12 (1986) 531-544.

[45] R. Caneel, Social signaling in decision making, Massachusetts Institute of Technology, 2005. https://pdfs.semanticscholar.org/4e21/835d017ca94e430b797a1846c95cea642a80.pdf.

[46] S. Robinson, Simulation: the practice of model development and use, 2nd Edition, Palgrave, London, 2014.

[47] R.W. McHaney, Understanding computer simulation, Ventus/Bookboon.com, Copenhagen, 2009. 
[48] R.W. McHaney, Computer Simulation: A Practical Perspective, Academic Press, San Diego, 1991.

[49] J.D.W. Morecroft, Strategic Modelling and Business Dynamics, John Wiley \& Sons, 2015.

[50] T.R. Willemain, Insights on modeling from a dozen experts, Operations Research. 42 (1994) 213-222.

[51] T.R. Willemain, Model formulation: what experts think about and when, Operations Research. 43 (1995) 916-932.

[52] O. Balci, R.E. Nance, Simulation model development environments: A research prototype., Journal of the Operational Research Society. 38 (1987) 753-763.

[53] O. Balci, A life cycle for modeling and simulation, Simulation: Transactions of the Society for Modeling and Simulation International. 88 (2012) 870-883.

[54] M. Pidd, Systems modelling: theory and practice, John Wiley \& Sons, 2004.

[55] S. Robinson, Simulation: the practice of model development and use, Wiley, Chichester, 2004.

[56] P. Aveyard, K.K. Cheng, J. Almond, E. Sherratt, R. Lancashire, T. Lawrence, C. Griffin, O. Evans, Cluster randomised controlled trial of expert system based on the transtheoretical (“stages of change”) model for smoking prevention and cessation in schools, BMJ. 319 (1999) 948-953.

[57] R.G. Sargent, Verification and validation of simulation models, in: S.J.B. Johansson, M.-T. J, H. J, Y. E (Eds.), 2010 Winter Simulation Conference, IEEE, Baltimore, MD, 2010: pp. 166188.

[58] R.G. Sargent, R.E. Nance, C.M. Overstreet, S. Robinson, J. Talbot, The simulation project lifecycle: Models and realities, in: F.L. Perrone, F.L. Wieland, J. Liu, B.G. Lawson, D.M. Nicol, R.M. Fujimoto (Eds.), 38th Winter Simulation Conference, IEEE, Monterey, CA, 2006: pp. 863-871.

[59] A.M. Law, Simulation Modeling and Analysis, McGraw-Hill, Boston, MA, 2007.

[60] J. Forrester, Industrial dynamics, Pegasus Communications, Waltham, MA, 1961.

[61] G.P. Richardson, System dynamics, the basic elements of, in: Complex Systems in Finance and Econometrics, Springer, New York, 2011: pp. 856-862. 
[62] J. Sterman, Business dynamics: systems thinking and modeling for a complex world, Volume 19, Irwin/McGraw-Hill, Boston, 2000.

[63] G. Coyle, The practice of system dynamics: milestones, lessons and ideas from 30 years experience, System Dynamics Review. 14 (1998) 343-365.

[64] J.B. Homer, G.B. Hirsch, System dynamics modeling for public health: background and opportunities, American Journal of Public Health. 96 (2006) 452-458.

[65] K.A. Stave, A system dynamics model to facilitate public understanding of water management options in Las Vegas, Nevada, Journal of Environmental Management. 67 (2003) 303-313.

[66] J.D.W. Morecroft, S. Robinson, Explaining puzzling dynamics: comparing the use of system dynamics and discrete-event simulation, in: Proceedings of the 23rd International Conference of the System Dynamics Society, Boston, MA, 2005.

[67] S. Brailsford, N. Hilton, A comparison of discrete event simulation and system dynamics for modelling healthcare systems, in: Proceedings of the 26th Meeting of the ORAHS Working Group 2000, Glasgow Caledonian University, Glasgow, Scotland, 2001.

[68] O. Balci, Guidelines for Successful Simulation Studies, in: O. Balci, R.P. Sadowski, R.E. Nance (Eds.), 22nd Winter Simulation Conference, IEEE, New Orleans, 1990: pp. 25-32.

[69] D.C. Lane, You just don’t understand me: models of failure and success in the discourse between system dynamics and discrete event simulation, LSE OR. (2000).

[70] R.G. Coyle, Representing Discrete Events in System Dynamics Models: A theoretical Application to Modelling Coal Production, Journal of the Operational Research Society. 36 (1985) 307-318.

[71] H.Y. Mak, System dynamics and discrete event simulation modelling, Department of Statistical and Mathematical Sciences. London School of Economics and Political Science, London, 1993.

[72] A.A. Tako, Exploring the model development process in discrete-event simulation: insights from six expert modellers, Journal of the Operational Research Society. 66 (2015) 747-760.

[73] A. Borshchev, The Big Book of Simulation Modeling. Multimethod Modeling with AnyLogic 6, AnyLogic North America, Chicago, 2013. 
[74] A. Green, Verbal protocol analysis in language testing research: A handbook (Vol. 5), Cambridge University Press, Cambridge, 1998.

[75] J.F. Bard, The Use of Simulation in Criminal Justice Policy Evaluation, Journal of Criminal Justice. 66 (1978) 99-116.

[76] N.K. Kwak, P.J. Kuzdrall, M.J. Schniederjans, Felony case scheduling policies and continuances: A simulation study, Socio-Economic Planning Sciences. 18 (1984) 37-43.

[77] G.B. Cox, P. Harrison, C.R. Dightman, Computer simulation of adult sentencing proposals, Evaluation and Program Planning. 1 (1978) 297-308.

[78] R. Korporaal, A. Ridder, P. Kloprogge, R. Dekker, An analytic model for capacity planning of prisons in the Netherlands, Journal of the Operational Research Society. 51 (2000) 1228-1237.

[79] P. Grove, J. Macleod, D. Godfrey, Forecasting the Prison Population, OR Insight. 11 (1998) 39.

[80] K.A. Ericsson, H.A. Simon, Protocol analysis; Verbal reports as data (revised edition), Bradford books/MIT Press, Cambridge, MA, 1993.

[81] R. McHaney, A.A. Tako, S. Robinson, Model building in system dynamics and discrete-event simulation: A comparison of analysts’ language, in: 2014 Operational Research Society Simulation Workshop, SW 2014, 2014.

[82] I. Chiu, F.A. Salustri, Understanding Design Concept Identification, in: J.S. Gero (Ed.), Design Computing and Cognition '12, 1st ed., Springer Netherlands, Dordrecht, 2014: pp. 625-642. doi:10.1007/978-94-017-9112-0.

[83] J.W. Pennebaker, R.L. Boyd, K. Jordan, K. Blackburn, The development and psychometric properties of LIWC2015, Austin, Texas, 2015. doi:10.15781/T29G6Z.

[84] Production Modeling, MedModel Process Simulation Software Case Study: Bupa Cromwell Hospital, Production Modelling. (2015). http://www.simulation.co.uk/casestudies/simulation/bupa-cromwell-hospital.html (accessed January 1, 2015).

[85] S.H. Jacobson, S.N. Hall, J.R. Swisher, Discrete-event simulation of health care systems, in: R.W. Hall (Ed.), Patient Flow: Reducing Delay in Healthcare Delivery: International Series in Operations Research \& Management Science Volume 19, Springer USA, 2006: pp. 211-252. 
[86] Production Modeling, Walkers Simulation Case Study, Production Modelling. (2015). http://www.simulation.co.uk/case-studies/simulation/walkers.html (accessed January 1, 2015).

[87] R.B. Detty, J.C. Yingling, Quantifying benefits of conversion to lean manufacturing with discrete event simulation: A case study, International Journal of Production Research. 38 (2010) 429-445.

[88] R.W. McHaney, Development of a generic SIMNET II simulation package for undirectional, sideloading AGV systems, Winter Simulation Conference Proceedings 1995. (1995). doi:10.1109/WSC.1995.478865.

[89] A.K. Sengupta, B. Das, J. Pemberton Cyrus, Performance improvement analysis of a supermarket checkstand: A computer simulation approach, International Journal of Productivity and Performance Management. 59 (2009) 37-50.

[90] A.P. Iannoni, R. Morabito, A discrete simulation analysis of a logistics supply system, Transportation Research Part E: Logistics and Transportation Review. 42 (2006) 191-210.

[91] AnyLogic, Modeling of Banca d'Italia back office system, AnyLogic Website. (2017). https://www.anylogic.com/modeling-of-banca-d-italia-back-office-system/ (accessed September 17, 2017).

[92] N. Ghaffarzadegan, J. Lyneis, G.P. Richardson, How small system dynamics models can help the public policy process, System Dynamics Review. 27 (2011) 22-44. doi:10.1002/sdr.442.

[93] R. Wong, S.Y. Sheng, A Business Application of the System Dynamics Approach: Word-ofMouth and Its Effect in an Online Environment, Technology Innovation Management Review. 2 (2012).

[94] J.M. Lyneis, K.G. Cooper, S.A. Els, Strategic management of complex projects: a case study using system dynamics, System Dynamics Review. 17 (2001) 237-260.

[95] H.A. Akkermans, K.E. Van Oorschot, Relevance assumed: a case study of balanced scorecard development using system dynamics, Journal of the Operational Research Society. 56 (2005) 931-941.

[96] AnyLogic, Major US airline decides NOT to charge additonal fees, AnyLogic Website. (2017). https://www.anylogic.com/major\%0A-\%0Aus\%0A-\%0Aairline\%0A- 
\%0Adecides\%0A-\%0Anot\%0A-\%0Ato\%0A-\%0Acharge\%0A-\%0Aadditional\%0A-\%0Afees/ (accessed September 17, 2017).

[97] Z. Kristekova, M.C. Jurisch, M. Schermann, H. Krcmar, Consolidating findings from business process change case studies using system dynamics: The example of employee morale, Knowledge Management \& E-Learning: An International Journal. 4 (2012) 455-480.

[98] K. Quinn, B. Monroe, M. Crespin, M. Colaresi, D. Radev, How to Analyze Political Attention With Minimal Assumptions and Costs, American Journal of Political Science. 54 (2010) 209228.

[99] T. Shanahan, C. Shanahan, What is disciplinary literacy and why does it matter?, Topics in Language Disorders. 32 (2012) 7-18.

[100] J. Grimmer, B.M. Stewart, Text as data: The promise and pitfalls of automatic content analysis methods for political texts, Political Analysis. (2013) mps028.

[101] D.J. Gerner, P.A. Schrodt, R.A. Francisco, J.L. Weddle, Machine coding of event data using regional and international sources, International Studies Quarterly. 38 (1994) 91-119.

[102] T. McEnery, R. Xiao, Y. Tono, Corpus-based language studies: An advanced resource book, Taylor \& Francis, 2006.

[103] D.R. Rice, C. Zorn, Corpus-Based Dictionaries for Sentiment Analysis of Specialized Vocabularies, in: Proceedings of NDATAD, London, 2013: pp. 1-17.

[104] S. Rude, E.-M. Gortner, J. Pennebaker, Language use of depressed and depression-vulnerable college students, Cognition \& Emotion. 18 (2004) 1121-1133.

[105] Harvard University, General Inquirer, (2002). http://www.wjh.harvard.edu/ inquirer/ (accessed April 4, 2018).

[106] University of Pittsburgh, Subjectivity Lexicon, Multi-Perspective Question Answering. (2014). http://mpqa.cs.pitt.edu/ (accessed April 4, 2018). 
APPENDIX A: Experiment 1 SD and DES Corpuses Compared to LIWC Corpus Norms

\begin{tabular}{lrrrrr} 
& \multicolumn{5}{c}{ Summary Variables } \\
\cline { 2 - 6 } & Word Count & Analytical Thinking & Clout & Authentic & Emotional Tone \\
\hline Variable & WC & Analytic & Clout & Authentic & Tone \\
\hline SD & 18985 & 28.78 & 57.67 & 35.25 & 6.09 \\
DES & 26986 & 22.83 & 58.38 & 47.33 & 13.20 \\
LIWC (Overall) & $11,921.82$ & 56.34 & 57.95 & 49.17 & 54.22 \\
LIWC (Expressive Writing) & 408.94 & 44.88 & 37.02 & 76.01 & 38.60 \\
LIWC (Natural Speech) & 794.17 & 18.43 & 56.27 & 61.32 & 79.29 \\
\hline
\end{tabular}

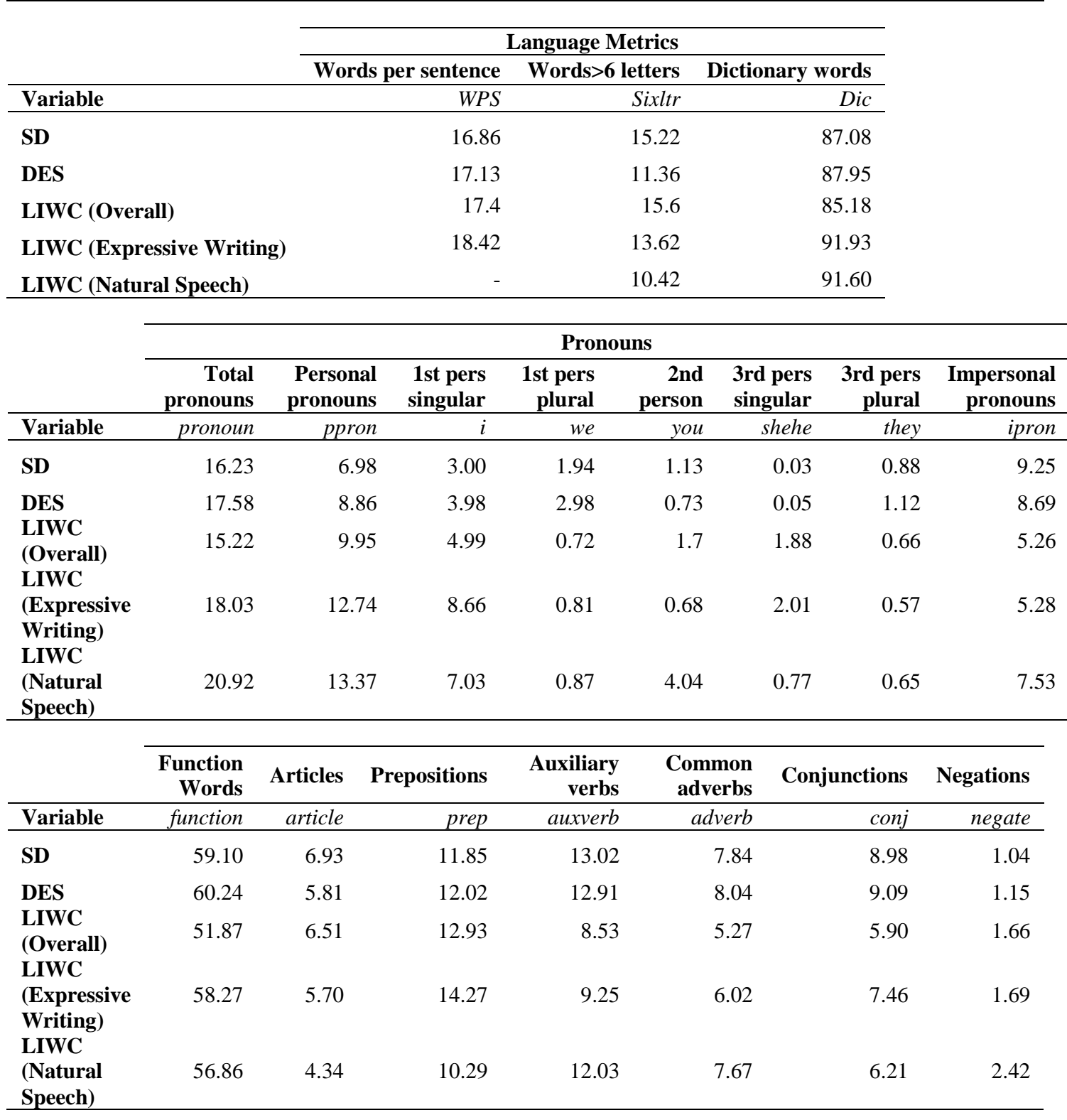




\begin{tabular}{lrrrrrr} 
& Regular verbs & Adjectives & Comparatives & Interrogatives & Numbers & Quantifiers \\
\hline Variable & $v e r b$ & $a d j$ & compare & interrog & number & quant \\
\hline SD & 19.81 & 5.61 & 2.31 & 2.12 & 3.64 & 2.45 \\
DES & 22.00 & 4.22 & 1.85 & 1.95 & 3.77 & 2.21 \\
$\begin{array}{l}\text { LIWC } \\
\text { (Overall) }\end{array}$ & 16.44 & 4.49 & 2.23 & 1.61 & 2.12 & 2.02 \\
$\begin{array}{l}\text { LIWC } \\
\text { (Expressive }\end{array}$ & 18.63 & 4.52 & 2.42 & & & \\
$\begin{array}{l}\text { Writing) } \\
\text { LIWC } \\
\text { (Natural }\end{array}$ & & & & & & \\
Speech) & 21.01 & 4.13 & 2.35 & 2.49 & 2.19 & 2.35 \\
\hline
\end{tabular}

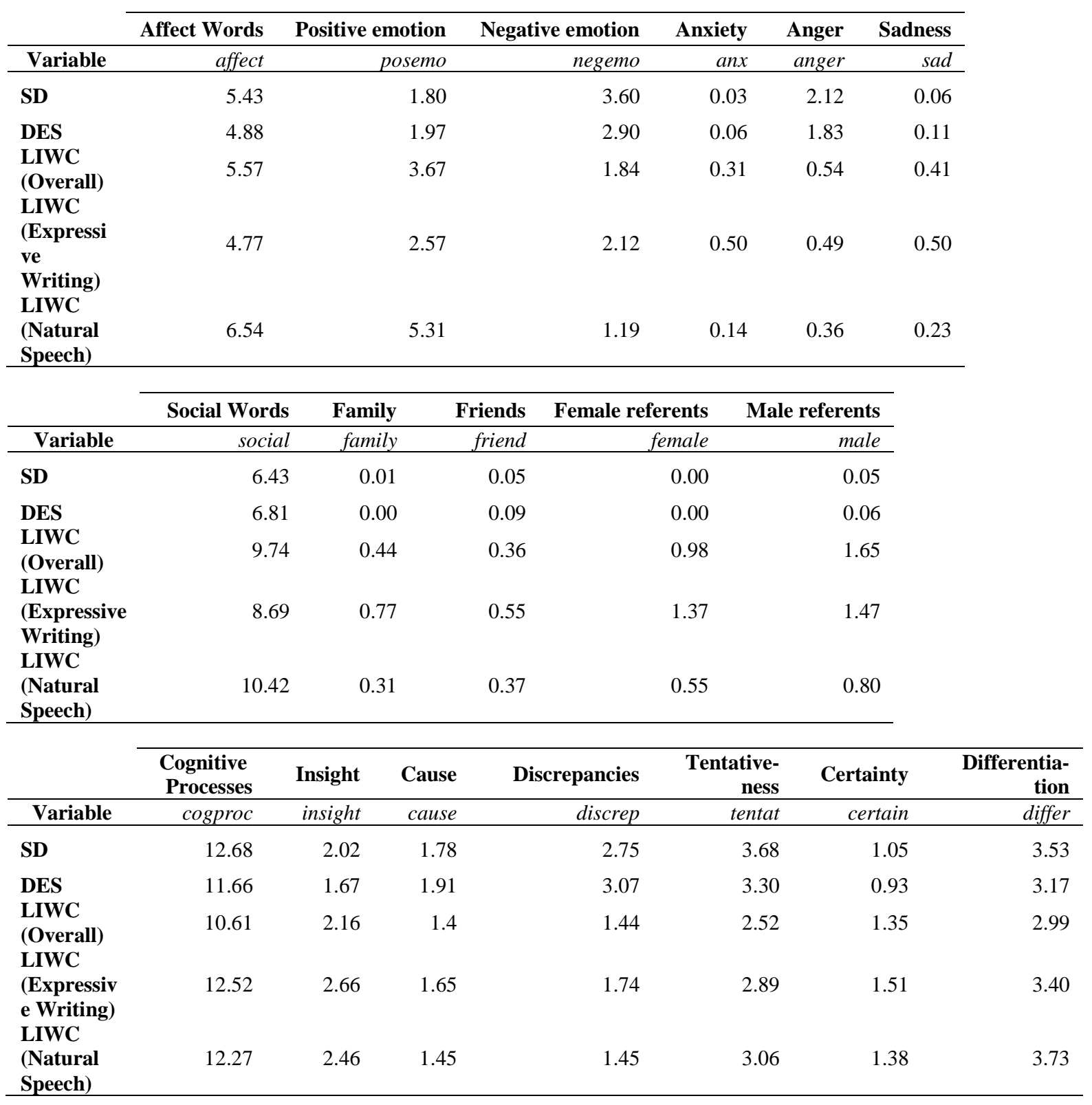




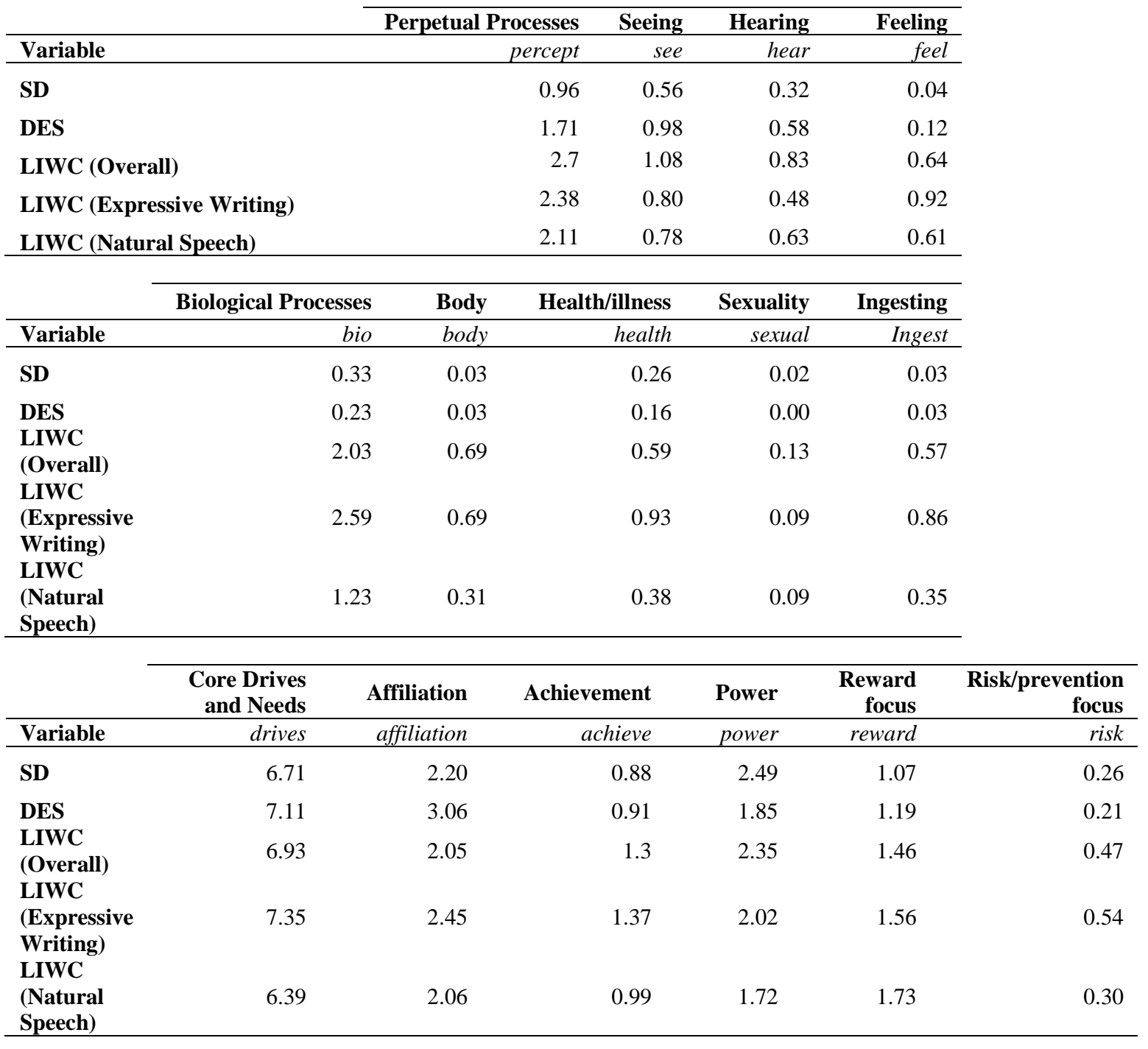

\begin{tabular}{lrrr} 
& \multicolumn{3}{c}{ Time Orientation } \\
\cline { 2 - 4 } & Past focus & Present focus & Future focus \\
\hline Variable & focuspast & focuspresent & focusfuture \\
\hline SD & 1.89 & 14.81 & 2.70 \\
DES & 1.68 & 15.88 & 3.32 \\
LIWC (Overall) & 4.64 & 9.96 & 1.42 \\
LIWC (Expressive Writing) & 5.83 & 10.45 & 1.85 \\
LIWC (Natural Speech) & 3.78 & 15.28 & 1.45 \\
\hline
\end{tabular}

\begin{tabular}{lrrrr} 
& Relativity & Motion & Space & Time \\
\hline \multicolumn{1}{c}{ Variable } & relativ & motion & space & time \\
\hline SD & 12.96 & 2.65 & 5.57 & 5.05 \\
DES & 14.90 & 3.99 & 5.67 & 5.59 \\
$\begin{array}{l}\text { LIWC } \\
\text { (Overall) }\end{array}$ & 14.26 & 2.15 & 6.89 & 5.46 \\
$\begin{array}{l}\text { LIWC } \\
\text { (Expressive }\end{array}$ & 16.19 & 2.58 & 6.96 & 7.01 \\
$\begin{array}{l}\text { Writing) } \\
\text { LIWC } \\
\text { (Natural }\end{array}$ & 12.12 & 2.20 & 5.86 & 4.28 \\
Speech) & & & & \\
\hline
\end{tabular}




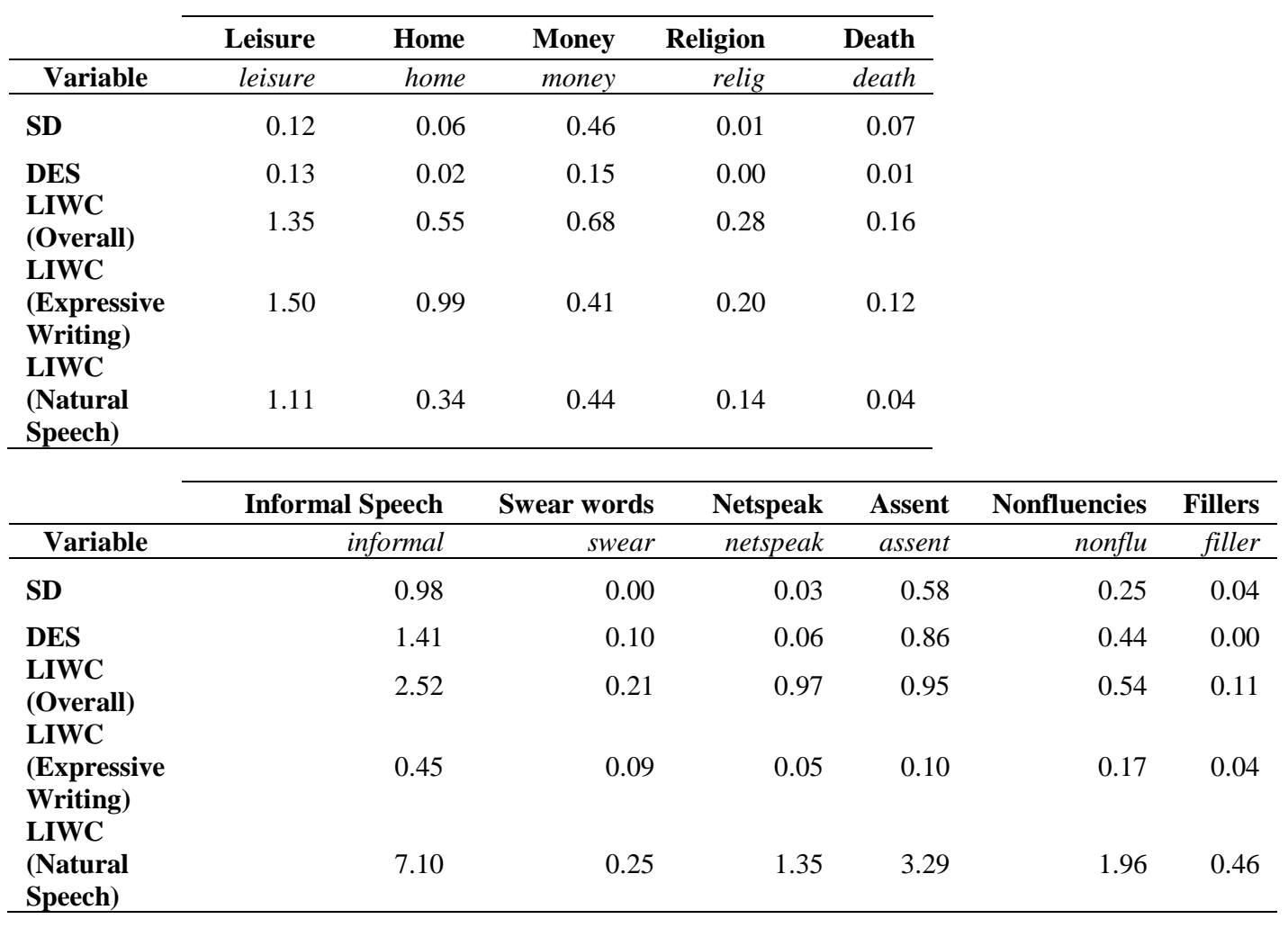

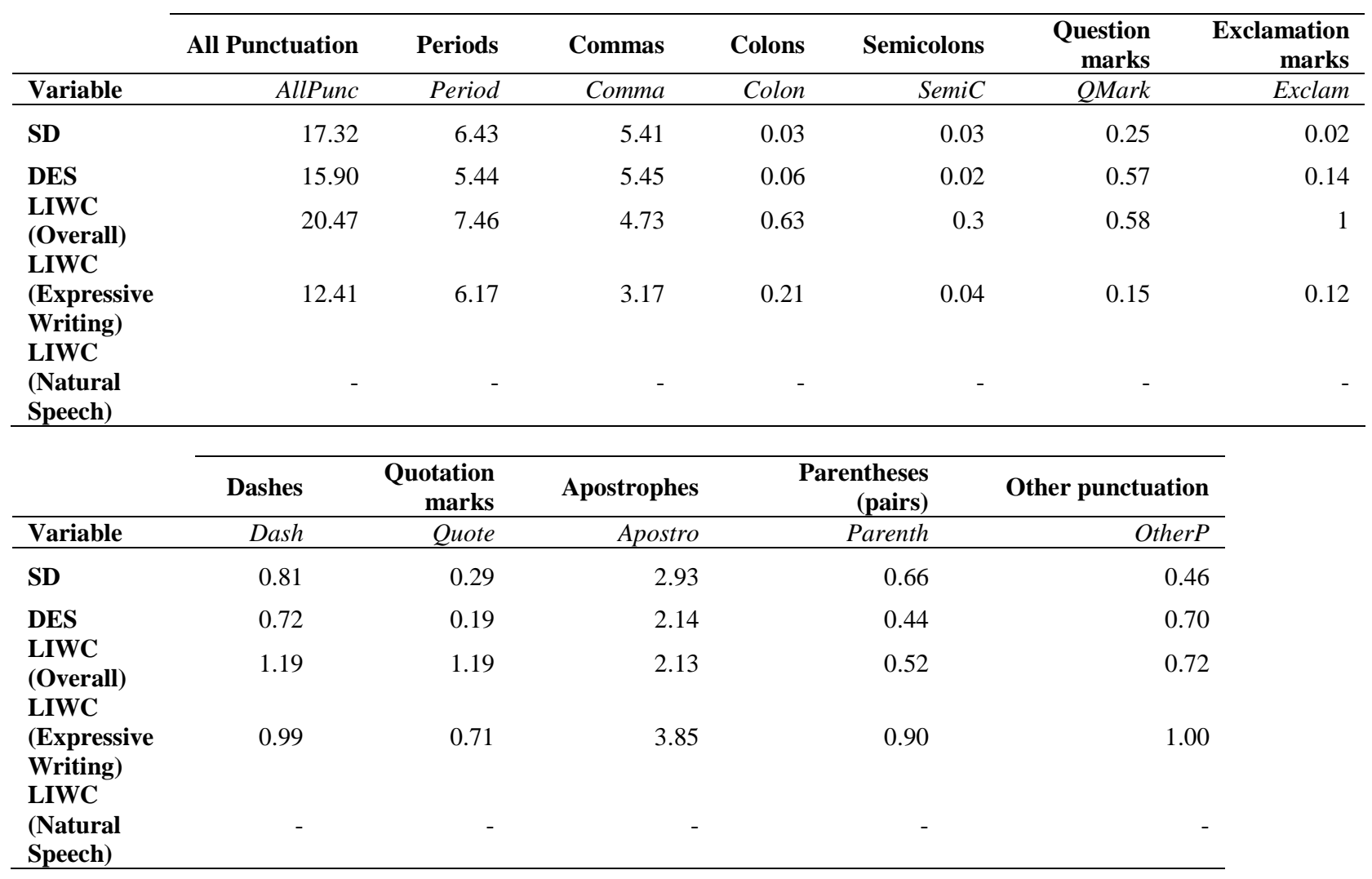

